\title{
ACCELERATING URBAN TRANSITION: AN APPROACH TO GREENING THE BUILT ENVIRONMENT
}

\author{
ANDREA BOERI, JACOPO GASPARI, VALENTINA GIANFRATE \& DANILA LONGO \\ Department of Architecture, University of Bologna, Italy
}

\begin{abstract}
The Bologna Adaptation Plan, recently adopted by the City authorities to address the way the city of tomorrow will coop with climate change effects, suggests some effective measures to mitigate and reduce the impacts of urban heat island [UHI] and heat waves. Among the suggested actions, the greening of in-between spaces of the dense built environment and the introduction of new green surfaces (roof and facades) seem to offer interesting perspectives. The paper describes a research activity run by the Department of Architecture and the Municipality of Bologna to investigate how to define the best arrangement of greening with the aim to optimize the impact on outdoor comfort conditions. After analysing UHI, the related parameters and the mitigation effect produced by green surfaces, some demo sites were assumed as test bed to simulate different green layout. Models and simulations were performed using ENVIMET, a software recognized in the scientific literature as one of the most used tool at urban scale. Once boundary conditions were modelled and all the main features of the sites were properly modelled, simulations were run in order to compare different scenarios coming from a number of architectural, economical and practical constraints. The results are then compared with other factors, related to the social aspects, the use of the spaces, the perception of the sites, etc. Two demo sites were investigated in two of the densest parts of the city of Bologna and one in the historic city center was definitely implemented as a temporary initiative coupling the environmental challenge with the opportunity to socially reshape a fragment of old city. This microintervention represents the first experimental phase to strengthen the urban transition of the historic city center in the perspective to realize no-disruptive transformations of the open public spaces, improving the users' wellbeing and comfort.
\end{abstract}

Keywords: urban transition, regeneration, greening actions, sustainable design, thermal comfort.

\section{INTRODUCTION}

The city of Bologna is facing some important changing related both to ongoing regeneration processes and to relevant mobility plans that will contribute in reshaping the consolidated urban fabric in the next decade. With the aim to provide a common framework and address all the projects toward a coherent and feasible vision, the Municipality recently adopted the Bologna Adaptation Plan, a document including some real local measures to make the city more resilient and capable to meet the climate change challenges. The Plan is the main outcome of a LIFE+ project named BLUE AP (Bologna Local Urban Environment Adaptation Plan for a Resilient City) [1], that was led by the Public Authorities to increase the reaction capacity of the city after several extreme events and conditions were experienced in the past decade.

The BLUE AP planning and testing actions were collected into guidelines for the Adaptation Plan definition with the ambition to be easily replicated to other medium-size Italian cities. Bologna represents a pilot-city in this field being the first city in Italy to adopt a plan for facing climate changes with a dedicated, specific and creative tool. The process, involving citizens and key stakeholders, defined six main pillars on which the Plan is based:

1. including adaptation measures in the City's Building Code - with aim to envisage clear and explicit incentives for adapting the built environment to more efficient management solutions of climate change effects; 
2. defining guidelines for improving infrastructural reactions during extreme meteorological events;

3. launching a greening campaign for outdoor comfort conditions for mitigation solutions in case of extreme conditions;

4. improving the rainwater harvesting capacity and transform paved surfaces to increase draining and diminishing flooding risks;

5. including measures for collecting rainwater in order to reduce water shortage in case of extreme conditions;

6. raising awareness about the risks associated with climate change and promote insurance schemes, by informing companies and citizens..

According to this framework a cooperation between the Municipality of Bologna and the University of Bologna - Department of Architecture was established to investigate possible solutions for urban and building regeneration taking into account the Adaptation Plan paradigms and to accelerate greening actions especially in quite consolidated and dense contexts. This paper presents the methodology approach adopted, the simulation and application of some solutions in the urban context.

\section{STATE OF THE ART AND BACKGROUND}

The relation between the structure of the cities and the effects of urban heat island [UHI] is a quite well investigated issue by the scientific community [2]-[4], while the outcomes and the impacts of potential mitigation or adaptation actions are still under discussion. Thus, the Technology Research Unit of the Department of Architecture (UNIBO) approached the request to accelerate greening actions to support urban transition with a very practical way: accepting the most relevant and consolidated assumption and selecting the most interesting locations where simulations and tests should be conducted in order to obtain a feedback about the proposed solutions. According to Asimakopoulos et al. [5], UHI is assumed as a climatic phenomenon where urban areas have higher air temperature than their rural surroundings as a result of anthropogenic modifications of land surfaces, pattern of urban fabric, building arrangement, significant energy use and its consequent generation of waste heat. This phenomenon behaves as a dome of stagnant warm air with a steady but weaker horizontal gradient of increasing temperature towards the heavily built-up areas of cities [6]. According to Oke [7], and Oke et al. [8] the different and combined causes contributing to UHI and more generally to uncomfortable environmental conditions can be grouped as follows [9]:

- anthropogenic heat including lighting, cooling and heating buildings which warm the urban atmosphere by conduction, convection, and radiation, influencing the energy balance in function of latitude and season of the year;

- air pollution, due to transportation and emissions, which influences the urban net all-wave radiation;

- surface waterproofing, referring to the predominance of impermeable surface especially for paved streets and public spaces which contributes to creating an evaporation deficit in the city;

- thermal properties of fabric, referring to the heat capacity, and consequently thermal inertia, of construction materials which absorb and retain more solar radiation than do rural soils and vegetation;

- $\quad$ surface geometry and buildings arrangement which influence wind speeds and urban radiation budget. 
A number of studies investigated the main factors influencing the urban microclimate and their impacts on buildings energy demand according to different levels of complexity as well as on the outdoor conditions [10], [11]. Bologna Adaptation Plan suggests the introduction of new green surfaces replacing existing paved areas, creating new green roofs and façades and thus a preliminary analysis of the potential deriving impacts was performed by the research team. A specific branch of the scientific literature is dedicated to deepen the effects of green surfaces in the built environment as a measure to reduce the discomfort and with the aim to achieve significant benefits. A number of studies and tests demonstrates that the air temperature in the immediate surroundings of a green surface is approximately equal to the open air one or, during the hottest days, higher of just 2-3 degrees [12]-[14], while a traditional roof or paved surface temperature can accumulate an amount of heat able to increase their superficial temperature of 30-40 degrees [15]-[17].

A greening strategy requires, however, to carefully consider some implications from a technical and managerial point of view: the choice and the installation of vegetation requires specific agro-technical competencies in order to select the proper species according to the conditions and the scope especially in the case of a green roof (and some differences occur in the case the roof covers an underground car park or a six storey building); a green surface has contained initial costs but requires constant maintenance activities that must be adequately planned and provided; the influence of vegetation both on the key climatic parameters and on the end users has to properly investigated in order to maximize the potential benefits. Vegetation usually ensures the variation of relative humidity, the absorption of fine dust, the conditioning of the air-motions, the increasing of oxygen concentration, the temperature control, etc. The physiological activities of vegetation impacting on the built environment conditions are summarized in Table 1.

Table 1: Vegetation physiological activities and related benefits (source: Giacomello, E., Copertura a verde e risorsa idrica. Implicazioni tecnologiche e benefici per l'ambiente urbano, Franco Angeli, Milan, 2012).

\begin{tabular}{|c|c|c|}
\hline physiological activity: & \multicolumn{2}{|l|}{ Phototropism } \\
\hline & \multicolumn{2}{|c|}{$\begin{array}{l}\text { leaves assume the best favourable configuration to intercept solar radiation } \\
\text { ensuring the processes of photosynthesis. }\end{array}$} \\
\hline \multicolumn{2}{|c|}{ Effects on the built environment } & Deriving benefits \\
\hline \multirow{3}{*}{\multicolumn{2}{|c|}{$\begin{array}{l}\text { Orienting perpendicularly to the light direction, } \\
\text { leaves intercept solar radiation before it reaches the } \\
\text { ground or the building surfaces. The foliage } \\
\text { represents a mobile shielding layer, able to self- } \\
\text { adjust according to the sun orientation. }\end{array}$}} & Reduction of impacting solar radiation \\
\hline & & Containment of surface temperatures \\
\hline & & $\begin{array}{l}\text { Reduction of the external surface emissivity at high } \\
\text { wavelength (and therefore reduction of radiant mean } \\
\text { temperature) }\end{array}$ \\
\hline \multirow[t]{2}{*}{ physiological activity: } & \multicolumn{2}{|l|}{ Photosynthesis } \\
\hline & \multicolumn{2}{|c|}{$\begin{array}{l}\text { Plants use solar radiation to convert water and carbon dioxide in their } \\
\text { nourishment (carbohydrates) }\end{array}$} \\
\hline \multicolumn{2}{|c|}{ Effects on the built environment } & Deriving benefits \\
\hline \multirow{3}{*}{\multicolumn{2}{|c|}{$\begin{array}{l}\text { Part of the incident solar radiation is captured by } \\
\text { plants to trigger the synthesis processes of } \\
\text { carbohydrates while reducing the solar radiation } \\
\text { conferred to the surface in the background. }\end{array}$}} & Reduction of mean radiant temperature \\
\hline & & Absorption of carbon dioxide (carbon fixation) \\
\hline & & Production of oxygen (photolysis) \\
\hline \multirow[t]{2}{*}{ physiological activity: } & \multicolumn{2}{|l|}{ Transpiration } \\
\hline & \multicolumn{2}{|c|}{ plants release water into the atmosphere in the form of vapour } \\
\hline \multirow{3}{*}{\multicolumn{2}{|c|}{$\begin{array}{l}\text { Effects on the built environment } \\
\text { The transition from liquid to vapor of water is } \\
\text { obtained dispersing solar radiation }\end{array}$}} & Deriving benefits \\
\hline & & Reduction of mean radiant temperature \\
\hline & & Ventilation and air movements around greened soil \\
\hline
\end{tabular}


The main benefits expected by adopting a greening strategy are therefore a reduction of the temperature in the space in-between buildings, due to the low emissivity that contrast the increasing air temperature values in the built environment, with positive mitigation impact in case of heat waves, an influence on the relative humidity that contributes in creating more comfortable conditions and a delay in conferring rainwater to collectors in case of extreme rainfall [18]. Nonetheless an increasing of the green surfaces has also positive effects in terms of social impacts on the citizen perception and use of the involved sites.

\section{DESIGN APPROACH AND SIMULATION MODELS}

The importance of considering the climate and micro-climate condition of the space inbetween the buildings emerged from the very beginning as one of the key aspect to include in the design approach for maximizing the potential impacts of greening solutions.

The research team focused on an intermediate scale between the city and the building: the district level was assumed as a preferential investigation field to explore how to greening solutions may positive influence the surroundings both reducing energy demand for cooling buildings and increasing quality and comfort condition of outdoor spaces [19]-[21].

Among the several areas where the Public Authorities is planning or implementing regeneration and transition actions, two sites were selected in the two densest portions of the urban fabric: the first one (Site 1) belongs to the Bolognina neighbourhood, in the north side of Bologna narrowing the railway central station, and the second one (Site 2) is located in the very center of the historic city. Fig. 1 shows the location of the two investigated sites in the city map.

\subsection{Site 1 description}

Most buildings of Bolognina dates back to the $50 \mathrm{~s}$ and the $60 \mathrm{~s}$ when the district was re-erected after the bombing of WWII and belongs to a social housing initiative. The urban fabric follows a regular rectangular grid according to a layout based on inner courtyards that were originally intended as green spaces but are actually used as car park.

A comprehensive regeneration project has been promoted focusing both on cost-effective design solution for retrofitting the buildings and on defining suitable options to re-arrange the outdoor spaces.
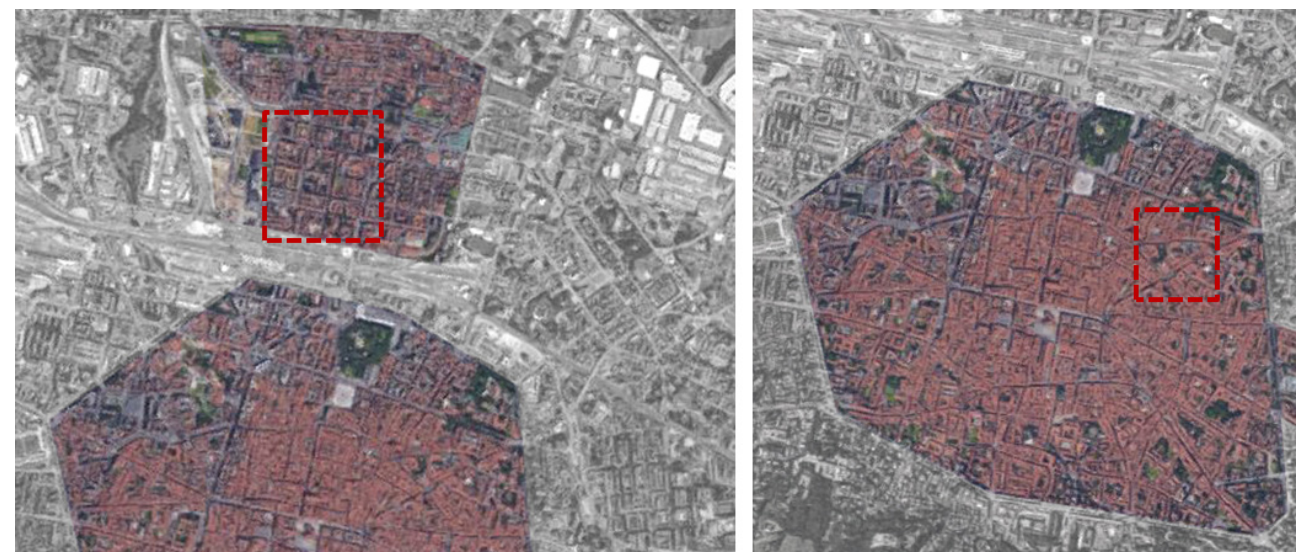

Figure 1: The Bologna map with highlighted the investigated sites. (a) Site 1; (b) Site 2. 

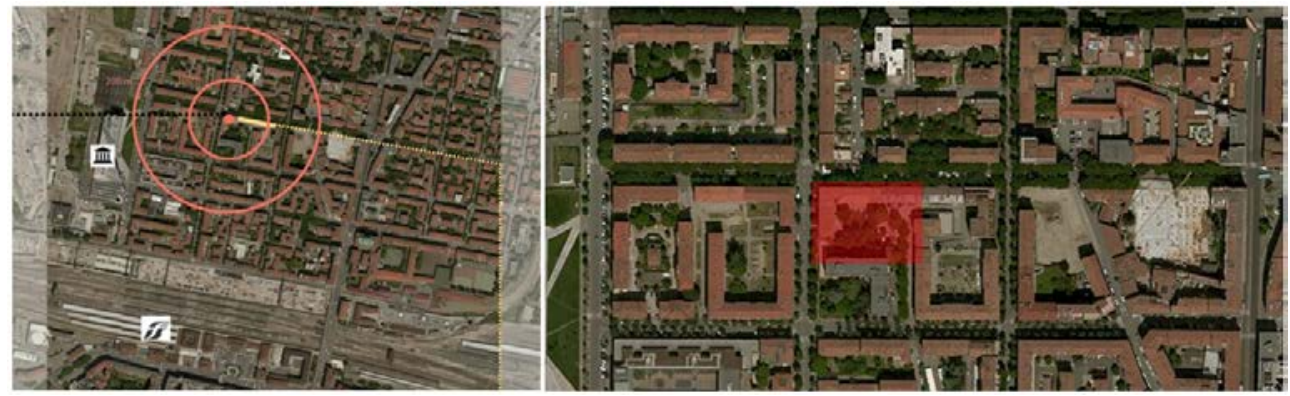

Figure 2: Site 1 location in Bolognina District.

A specific block representing the typical situation was selected to develop some simulations and design options within the activities of Ma Sustainable Design Studio at the Department of Architecture. The block is clearly divided in two main spaces by a building, North-South oriented, and the study focused on the North-West corner and courtyard. Fig. 2 provides a more detailed locations of the site.

\subsection{Site 2 description}

The city center represents the densest urban fabric of Bologna and the selected area, Piazza Scaravilli, is a courtyard confined on three sides by university buildings and on the fourth is separated from via Zamboni by a portico. The place is part of the main university of Bologna headquarter and at the same time is very closed to most of the cultural institutions of the city. However, the site, currently used as a parking area, suffers both of uncomfortable climate conditions due to the huge amount of paved surfaces and of social conflicts related to a misuse of the public spaces in the district. For this reason, the site and the whole area are part of broader regeneration project under the framework of ROCK (Regeneration and Optimization of Cultural heritage in creative and Knowledge cities) project, financed by the EU Horizon 2020 research and innovation programme under grant agreement No 730280. Within this framework, the study aims to analyse/simulate the site conditions to prepare a socio-climatic experiment, useful to test mitigation and regenerative actions to be implemented under the project auspices and goals. Fig. 3 provides a more detailed locations of the site.

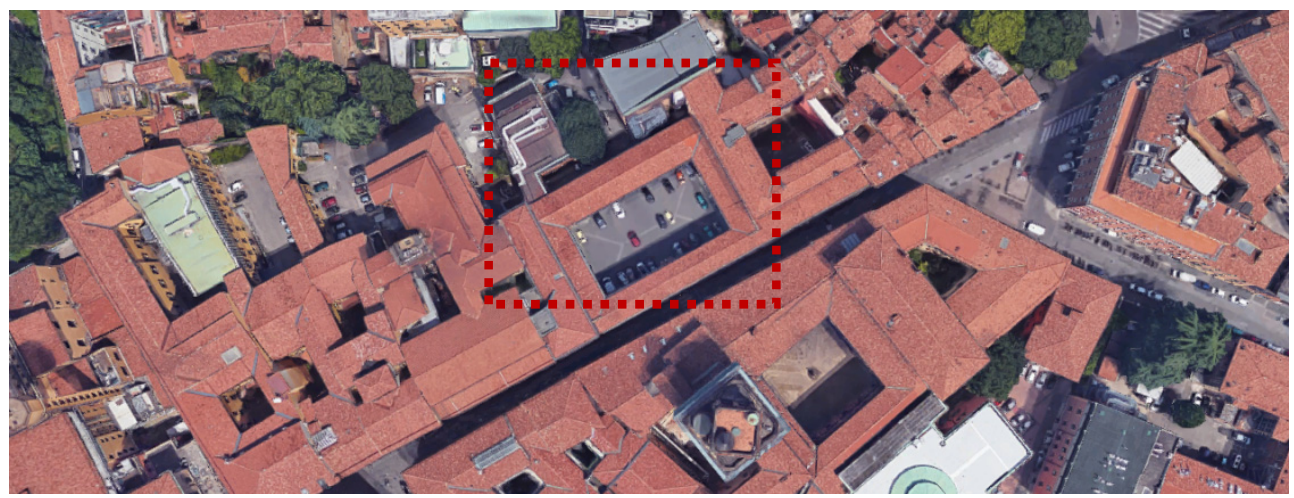

Figure 3: Site 2 location in the historic city center: piazza Scaravilli. 


\subsection{Assumptions and simulations}

Despite the microclimate condition represents only a part of a wider strategy to regenerate the district, outdoor comfort captured the team attention with reference to the correlation between the adoption of greening solutions and potential mitigation impact.

Comfort conditions of outdoor spaces depends on a huge number of inter-related factors dealing with the main geometrical and material features of the built environment, thus one of the main goal of the study was to provide a simplified method to visualize the conditions of a specific site before and after interventions. ENVI-met [22] simulation software was adopted for this purpose: it is a quite well known and diffuse tool used at urban scale that has been widely explored in the scientific literature [23]. ENVI-met is a three-dimensional microclimate model designed to simulate the surface-plant-air interactions in a urban environment with a typical resolution of 0.5 to 10 meters spatial grid and $10 \mathrm{sec}$ frame time. ENVI-met is a prognostic model based on the fundamental laws of fluid-dynamics and thermo-dynamics. ENVI-met enables to manage the main variables (air-temperature, wind-speed, relative humidity, etc.) and comfort Predicted Mean Vote index [PMV] [24], for creating isolines representations strictly connected to the site features.

The deriving outdoor maps provide a quite effective image of the impacts on the site allowing an easier decision-making process about design choices and options.

In the case of Site 1 a completely new courtyard layout was designed and the impacts of the proposed solutions on outdoor conditions were simulated before and after in order to evaluate the impacts and consider possible variations. Fig. 4 compares the courtyard layouts, while Figs 5, 6 and 7 offer some examples of the obtained outputs.

The deriving results are specific Outdoor-Microclimate-Maps indicated that there was a quite limited air-temperature variation in Site 1 while as Fig. 5 shows maximum wind speed value in the plot varies from $7.66 \mathrm{~m} / \mathrm{s}$ to $9.70 \mathrm{~m} / \mathrm{s}$ meaning the proposed layout facilitate natural ventilation and reduces still air zones (in blue). As Fig. 6 shows, relative humidity minimum (nearly $29 \%$ ) and maximum (nearly $45 \%$ ) values variations are quite limited while comfort conditions evaluated using PMV index seems to be positively influenced in the re-shaped
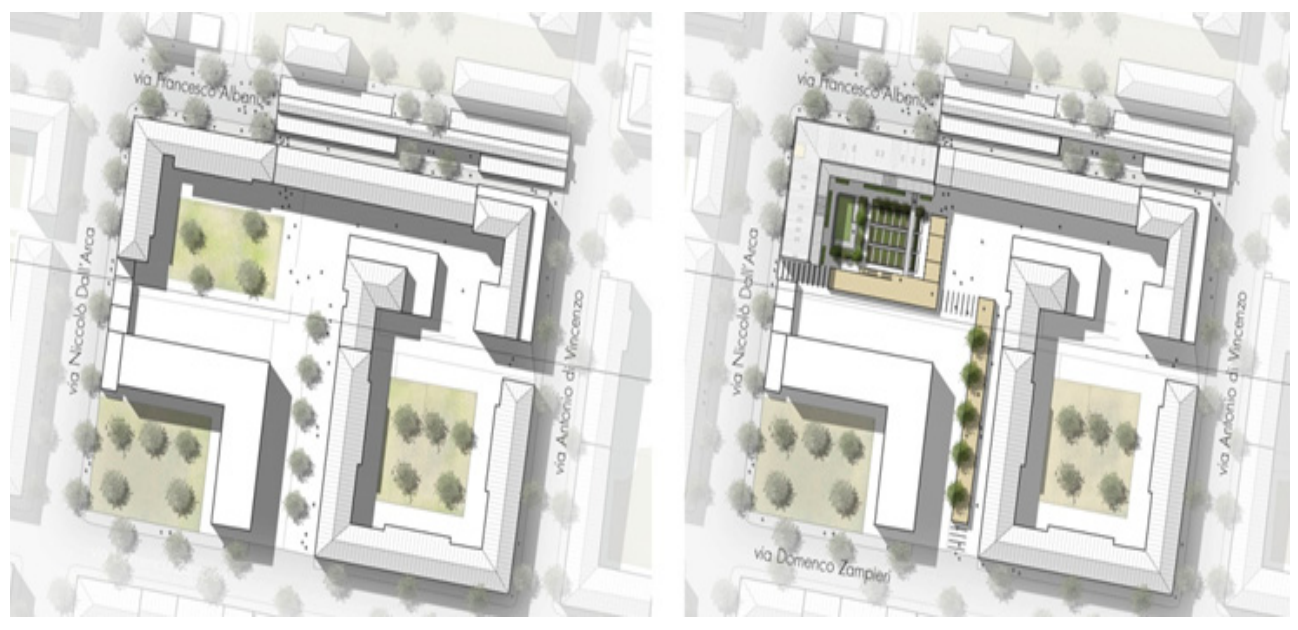

Figure 4: The current and the re-designed courtyard layout. 
north-west corner especially if compared with the residual portions. The same approach and simulation methodology was adopted on site 2 to evaluate how some design option should influence comfort condition starting from the assumption to provide a temporary re-arrangement of Piazza Scaravilli that replaces the current car park function with a green space for collective use. Simulation addressed the arrangement of green areas and this initial design brief was than translated into a concrete action.
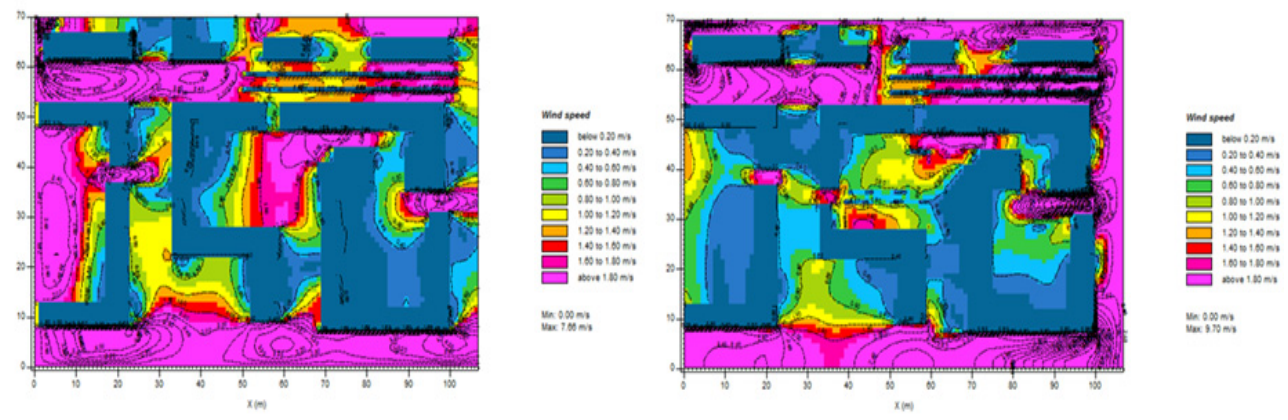

Figure 5: Wind speed according to the current and the re-designed courtyard layout.
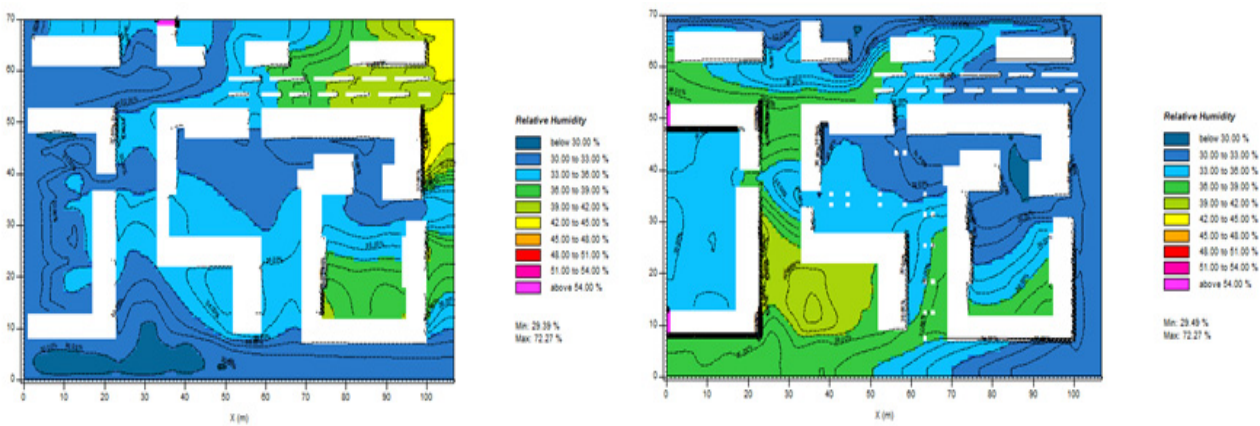

Figure 6: Relative humidity according to current and the re-designed courtyard layout.
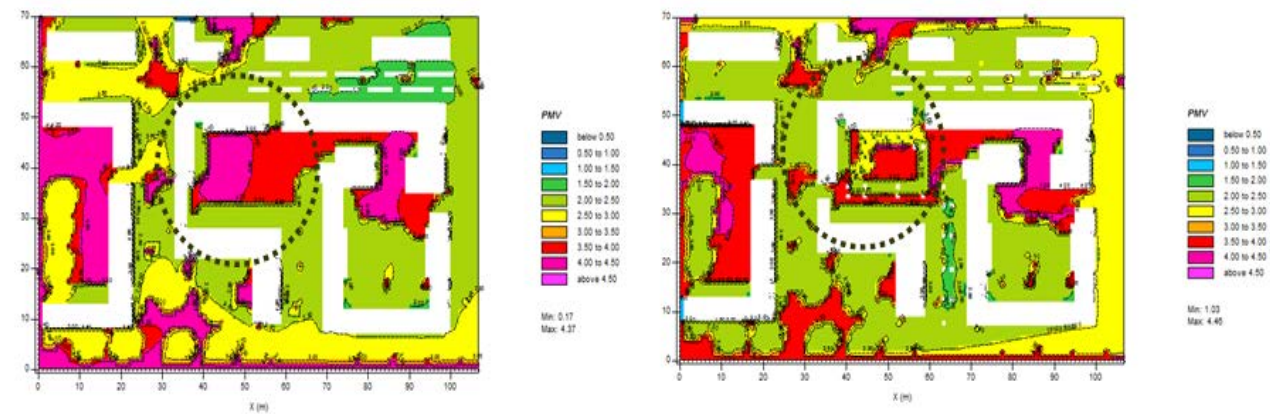

Figure 7: PMV according to current and the re-designed courtyard layout. 


\section{MICRO-INTERVENTION: SOCIAL AND CLIMATIC ASPECTS}

The deployment of a socio-climatic experiment is based on the introduction of a social and technological infrastructure to increase the resilience of the whole area with the aim to promote the transition with micro-design solutions at urban scale: punctual or micro-actions to trigger physical changes, but also to modify the perception and the relations between the communities that populate the place. This focus on open urban spaces is supported by a well-defined regulatory framework in the City of Bologna: a) the Residential Climate Adaptation Plan for the definition of pilot actions to promote an active stakeholder participation in accelerating the climate mitigation strategy and related initiatives; b) the Rules for the Care and Regeneration of Municipalities of Bologna, issued to coordinate and link a set of ongoing actions and projects through the active collaboration of local actors and entrepreneurs.

In the case of Scaravilli Square, the micro-intervention and installations were concentrated on the two sides of the square, leaving the surrounding porticos and the central passage free (for emergency transit). In terms of social impact, the action is aimed to involve both the residents and the students that enjoy the spaces of the university area in different and often conflicting ways. The project has been co-designed by students and city associations and activists, producing a participatory realization and a model of management based on cooperation. The adopted work methodology follows the ROCK research process and is translated into a co-design pilot workshop for Design and Architecture students at University of Bologna. During this pilot, some of the engagement models that will be implemented during the demonstration phase of the European project were tested, exploring the potential for mitigation of the urban environment, the possible implications on microclimate and interactions with the sustainable use and development of the territory, to stimulate accessibility, inclusion and sense of belonging to the place by inhabitants and students. The pilot envisaged a greening action placing some temporary wooden tanks to host vegetation combined with wooden decks operating as stages, passages or seats (see Fig. 8). The used materials were thought to be durable according to their temporary lifespan, easily replaceable, clean and maintainable: the idea is to realize a dynamic garden, to foster biodiversity and sociality. The proposed adaptive reuse of Scaravilli Square has not only environmental purposes (improvement of outdoor comfort; urban heat island mitigation; reduction of $\mathrm{CO}_{2}$ emissions), but also the aim to enable the quality of life of neighbourhood residents, by providing them with spaces for collective and multifunctional use (outdoor events, socialization spaces, temporary markets).

The idea is therefore to combine temporary and permanent transformations, in a perspective of sustainability and resilience as "potential for creating opportunities for new actions aimed at innovation and development" [25]. The great potential is to configure these spaces as places to activate the construction of resilient communities able to react creatively to changes [26]. The social experiment is aimed to support spontaneous forms of co-management and care of this space, based on low cost investment and high investment of design, testing environmentally sustainable construction technologies, materials and techniques that allow people to experience patterns of use before making permanent changes. Depending on the success of the action (monitored for two seasons), the progressive transformation of the square will enable a new model for public/semi-public space management that could be replicated in other neighbourhoods of Bologna. 


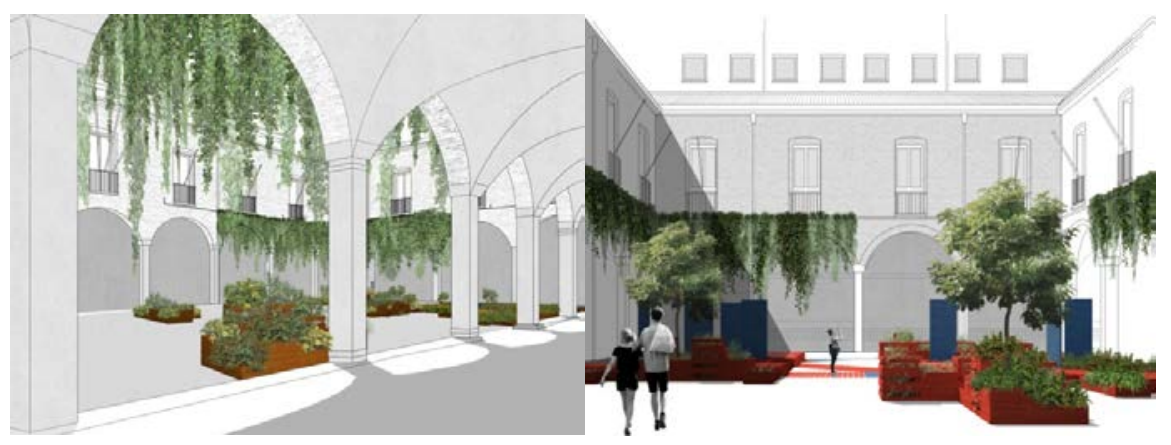

Figure 8: Views (a) and (b) of the dynamic garden in Scaravilli square elaborated during the co-design workshop.

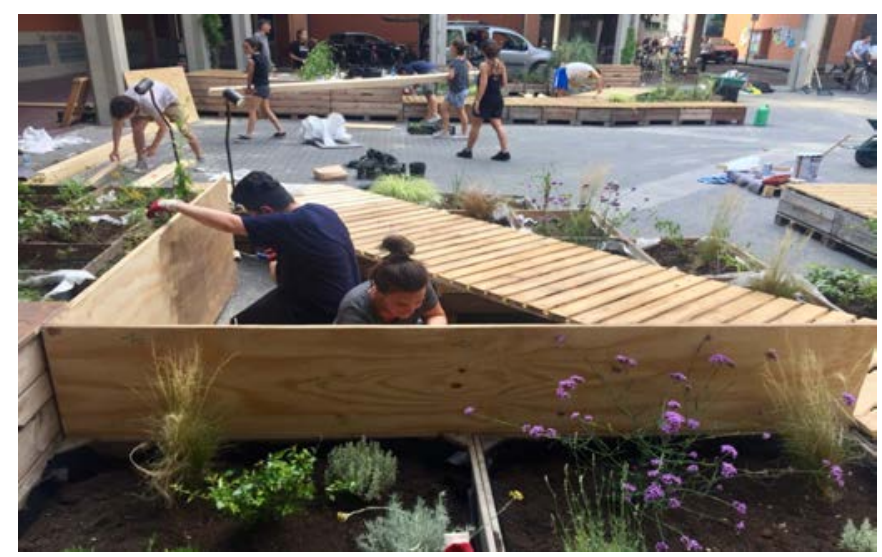

Figure 9: The co-construction phase realized with students and citizens associations.

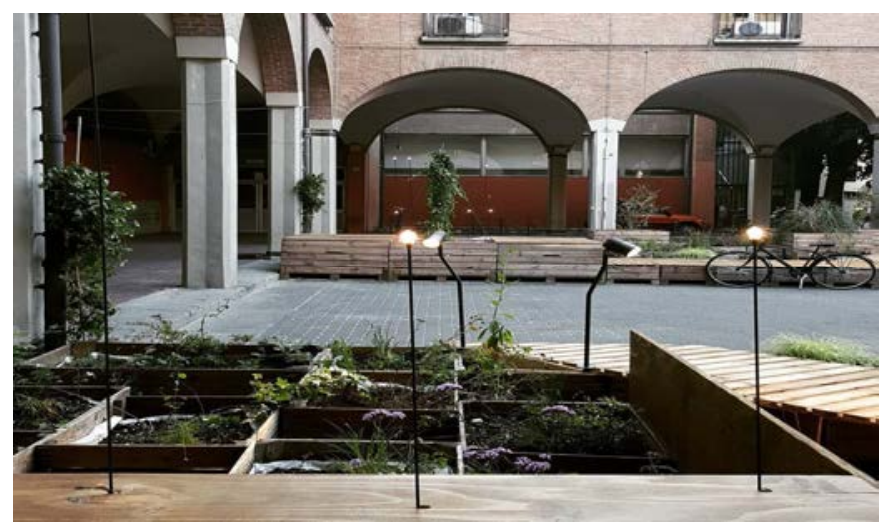

Figure 10: The final layout of the square, completed of light equipment sponsored by Viabizzuno. 


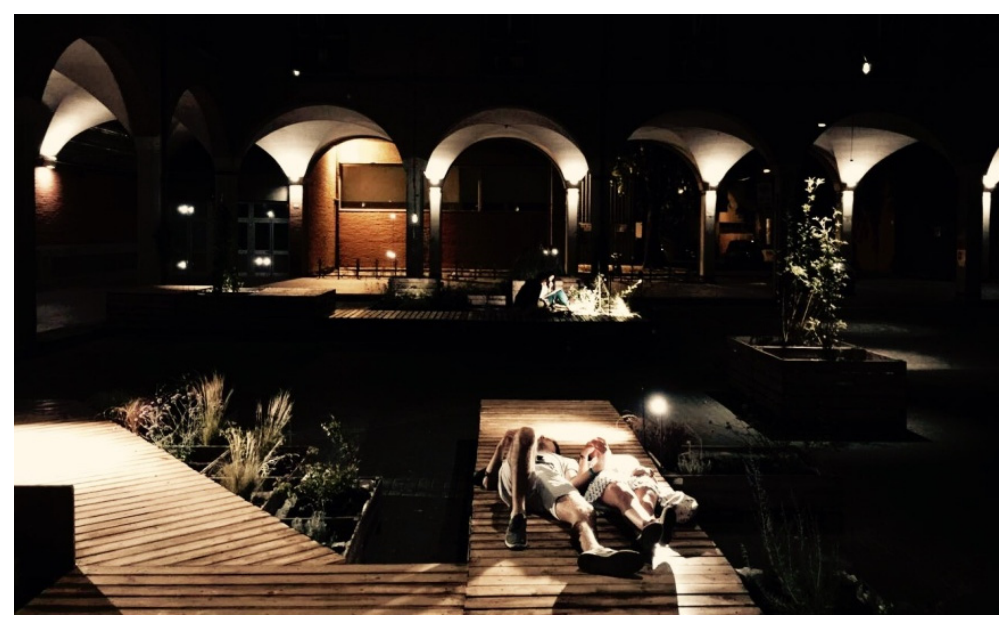

Figure 11: Night time in Scaravilli Square.

\section{CONCLUSIONS}

Open spaces represents the public service that most categories of citizens use daily with none demographic socio-economic discrimination of users. This is a common ground where people carry out the functional and leisure activities that characterized a community. The impact generated by open space involves the perception of quality of life and physical and psychological well-being of people, providing a place dedicated to social interaction and contact with the built and natural environment.

The transformation process that starts in those places foresees a regeneration not only physical-environmental but also socio-economic pursuing a wider transition strategy, recreating urban quality, accessibility and permeability. The choice of referring to microurban design seems particularly effective because it is sustainable in a period of shortage of public resources that traditionally finance interventions on the open space of the city.

The purpose of these interventions is to contribute to the improvement of the environmental, functional and aesthetic aspects of the city, having a positive impact on the real estate value of the entire areas in which they are incorporated and at the same time to create an ecosystem of actors implementing and managing the transformation, both in historical centers and in peripheral contexts.

The ultimate goal of the presented approach is to define a replicable and scalable model that supports the regeneration of very dense neighbourhoods starting from their open spaces. Transformation activities foresee the active involvement of citizens, associations, students, creative communities and private bodies in the co-production, safeguard and management of new elements and equipment. The analyzed areas have a great potential for replication in the context of Bologna city. Acting primarily on the public space is a possible strategy for transferring the concepts of "active citizenship", sustainable development, climatic risk, between local communities, starting from microscale interventions that will produce significant impacts on different spheres of urban, social, environmental quality. The actions envisaged have a high degree of scalability, combining temporary and permanent transformations, testing on the field not only the solutions more closely related to the specific context of intervention but, at the same time, checking their acceptance by resident communities, progressively promoting the re-appropriation and re-invention of public space. 


\section{REFERENCES}

[1] http://www.blueap.eu/site/en/il-progetto/ Accessed on: 22 Jul. 2017.

[2] Stone, B., The City and the Coming Climate: Climate Change in the Places We Live, Cambridge: Cambridge University Press; 2012.

[3] Santamouris, M., Energy and Climate in the Urban Built Environment, London: James \& James; 2011.

[4] Santamouris, M., Cooling the cities - A review of reflective and green roof mitigation technologies to fight heat island and improve comfort in urban environments. Solar Energy, 103, pp. 682-703, 2014.

[5] Asimakopoulos, D.N., Assimakopoulos, V.D., Chrisomallidou, N., Klitsikas, N., Mangold, D., Michel, P., Santamouris, M. \& Tsangrassoulis, A. Energy and Climate in the Urban Built Environment, Santamouris, M., ed. James \& James: London, UK, 2001.

[6] Oke, T.R., Boundary Layer Climates, Methuen and Co.: New York, NY, USA, 1987.

[7] Oke, T.R., Canyon geometry and the nocturnal urban heat island: Comparison of scale model and field observations. J. Climatol. 1, pp. 237-254, 1981.

[8] Oke, T.R., Johnson, G.T., Steyn, D.G. \& Watson, I.D., Simulation of surface urban heat islands under "ideal" conditions at night-part 2: Diagnosis of causation. Bound.Layer Meteorol., 56, pp. 339-358, 1991.

[9] Dernie D. \& Gaspari J., Building Envelope Over-Cladding: Impact on Energy Balance and Microclimate. Buildings, 5(2), pp. 715-735, 2015.

[10] Schneider, A. \& Maas, A. Einfluss des Mikroklimas auf das energetische und thermische Verhalten von Gebäuden am Beispiel des Standortes Kassel. Bauphysik, 32, pp. 348-358, 2010.

[11] Stupka, R. \& Kennedy, C. Impact of neighborhood density on building energy demand and potential supply via the urban metabolism. In ACEE Summer Study on Energy Efficiency in Buildings; American Council for an Energy-Efficient Economy: Washington, DC, USA, pp. 239-252, 2010.

[12] Hoyano, A., Climatological uses of plants for solar control and effects on the thermal environment of a building, Energy and Buildings, 11, pp. 181-199, 1998.

[13] Wilmers, F., Green for melioration of urban climate, Energy and Buildings, 11, pp. 289-299, 1988.

[14] Weiler, S. \& Scholz-Barth K., Green Roof System. A Guide to Planning, Design and Constructing Landscapes over Structure, John Wiley \& Sons, Hokoben, US, p. 320, 2009.

[15] Baskaran, B. \& Karen, L., Thermal performance of green roofs through field evaluation, National Research Council Canada, 2003. www.nrc-cnrc.gc.ca/obj/irc/doc/ pubs/nrcc46412/nrcc46412.pdf. Accessed on: 22 Jul. 2017.

[16] Yu, C. \& Hien Nyuk, W. Thermal benefits of city parks, Energy and Buildings 38, pp. 105-120, 2006.

[17] Feng, Chi, Meng, Q. \& Zhang, Y., Theoretical and experimental analysis of the energy balance of extensive green roofs Energy and Buildings 42, pp. 959-965, 2010.

[18] Gaspari J. \& Giacomello E., A study on energy and water management in green infill solutions and ground floor additions. Proceedings of CIB W115 Green Design Conference, pp. 118-123, 2012.

[19] Santamouris M. On the impact of urban climate on the energy consumption of buildings. Solar Energy, 70, pp. 201-216, 2001. 
[20] Allegrini, J., Dorera, V. \& Carmelieta, J., Influence of the urban microclimate in street canyons on the energy demand for space cooling and heating of buildings. Energy and Buildings, 55, pp. 823-832, 2012.

[21] Yaghoobiana, N. \& Kleissl, J., An indoor-outdoor building energy simulator to study urban modification effects on building energy use-Model description and validation. Energy and Buildings, 54, pp. 407-417, 2012.

[22] ENVI-met Available from: http://envi-met.com/. Accessed on: 22 Jul. 2017.

[23] Taleghani M., Outdoor thermal comfort within five different urban forms in the Netherlands. Building and Environment, 83, pp. 65-78, 2015.

[24] Gaspari J. \& Fabbri K., A study on the use of outdoor microclimate map to address design solutions for urban regeneration. Energy Procedia, 111, pp. 500-509, 2017.

[25] Adger W. N., Vulnerability, Global Environmental Change, Elsevier Ltd, 16 pp. 268 281, 2006.

[26] Gianfrate, V., Boeri, A., Longo, D. \& Lorenzo, V., Resilient communities. Social infrastructures for sustainable growth of urban areas. A case study, International Journal of Sustainable Development and Planning, 12(2), 2017. 